\title{
Publisher Correction: A systems view of spliceosomal assembly and branchpoints with iCLIP
}

Michael Briese, Nejc Haberman, Christopher R. Sibley (D), Rupert Faraway, Andrea S. Elser, Anob M. Chakrabarti, Zhen Wang, Julian König, David Perera, Vihandha O. Wickramasinghe, Ashok R. Venkitaraman, Nicholas M. Luscombe (D), Luciano Saieva, Livio Pellizzoni (D), Christopher W. J. Smith (D), Tomaž Curk (iD and Jernej Ule (iD)

Correction to: Nature Structural \& Molecular Biology https://doi.org/10.1038/s41594-019-0300-4, published online 30 September 2019. In the supplementary information originally posted for this article, the Supplementary Information PDF file did not contain the Supplementary Figs. or Tables; it contained only a title page with the authors' names and affiliations. The error has been corrected online.

Published online: 5 May 2021

https://doi.org/10.1038/s41594-021-00595-5

๑ The Author(s), under exclusive licence to Springer Nature America, Inc. 2021 